\title{
FATAL DISTRACTION? A COMPARISON OF THE CELL-PHONE DRIVER AND THE DRUNK DRIVER
}

\author{
David L. Strayer, Frank A. Drews, and Dennis J. Crouch \\ Department of Psychology \\ 380 S. 1530 E. Rm 502 \\ University of Utah \\ Salt Lake City, UT 84112, USA \\ E-mail: David.Strayer@utah.edu
}

\begin{abstract}
Summary: We used a high-fidelity driving simulator to compare the performance of cell-phone drivers with drivers who were legally intoxicated from ethanol. When drivers were conversing on either a hand-held or hands-free cell-phone, their reactions were sluggish and they attempted to compensate by driving slower and increasing the following distance from the vehicle immediately in front of them. By contrast, when drivers were legally intoxicated they exhibited a more aggressive driving style, following closer to the vehicle immediately in front of them and applying more force while braking. When controlling for driving difficulty and time on task, cell-phone drivers exhibited greater impairment than intoxicated drivers.
\end{abstract}

It is estimated that over 100 million cellular subscribers in the United States use their phones while driving (Cellular Telecommunications Industry, 2003; Goodman et al., 1999). Because of safety concerns associated with cell phone use while driving, several legislative efforts have been made to restrict cell phone use on the road (Hahn, Tetlock, \& Burnett, 2000; Hahn \& Dudley, in press). In most cases, the legislation restricts the use of hand-held phones but permits the use of hands-free phones while driving. In fact, several researchers have reported that driving is impaired by concurrent cell phone use (Alm \& Nilsson, 1995; Briem \& Hedman, 1995; Brookhuis, De Vries, \& De Waard, 1991; McKnight \& McKnight, 1993; Strayer \& Johnston, 2001; Strayer, Drews, \& Johnston, 2003); however, the precise impact of cell-phone driving on traffic safety is unknown. In their seminal article, Redelmeier and Tibshirani (1997) reported epidemiological evidence suggesting that "the relative risk [of being in a traffic accident while using a cell-phone] is similar to the hazard associated with driving with a blood alcohol level at the legal limit" (p. 465). If this finding can be substantiated in a controlled laboratory experiment, then these data would be of immense importance for public safety.

Here we report the result of a controlled study that directly compared the performance of drivers who were conversing on a cell-phone with the performance of drivers who were legally intoxicated with ethanol. We used a car-following paradigm in which participants followed an intermittently braking pace car while they were driving on a multi-lane freeway. Three conditions were studied: single-task driving (baseline condition), driving while conversing on a cell-phone (cell-phone condition), and driving with a blood alcohol concentration of $0.08 \mathrm{wt} / \mathrm{vol}$. (alcohol condition). The driving tasks were performed on a high-fidelity driving simulator. 


\section{METHOD}

Participants. Forty-one adults (26 male and 15 female) participated in the IRB approved study. Participants ranged in age from 22 to 45, with an average age of 25.7. All had normal or corrected-to-normal vision and a valid driver's license.

Stimuli and Apparatus. A PatrolSim high-fidelity driving simulator, manufactured by GE I-Sim was used in the study. A freeway road database simulated a 24-mile multi-lane beltway with on and off-ramps, overpasses, and two and three-lane traffic in each direction. A pace car, programmed to travel in the right-hand lane, braked intermittently throughout the scenario. Distractor vehicles were programmed to drive between 5\% and 10\% faster than the pace car in the left lane, providing the impression of a steady flow of traffic. Unique driving scenarios, counterbalanced across participants, were used for each condition in the study. Measures of realtime driving performance, including driving speed, distance from other vehicles, and brake inputs, were sampled at $30 \mathrm{~Hz}$ and stored for later analysis. Cellular service was provided by Sprint PCS. The cell-phone was manufactured by LG Electronics Inc. (model TP1100). For hands-free conditions, a Plantronics M135 headset (with ear piece and boom microphone) was attached to the cell-phone. Blood alcohol concentration levels were measured using an Intoxilyzer 5000, manufactured by CMI Inc.

\section{PROCEDURE}

The experiment was conducted in three sessions on different days. The first session familiarized participants with the driving simulator using a standardized adaptation sequence. The order of subsequent alcohol and cell-phone sessions was counterbalanced across participants. In these latter sessions, the participant's task was to follow the intermittently braking pace car driving in the right-hand lane of the highway. When the participant stepped on the brake pedal in response to the braking pace car, the pace car released its brake and accelerated to normal highway speed. If the participant failed to depress the brake, they would eventually collide with the pace car. That is, like real highway stop and go traffic, participants were required to react in a timely and appropriate manner to a vehicle slowing in front of them.

In the alcohol session, participants drank a mixture of orange juice and vodka $(40 \%$ alcohol by volume) calculated to achieve a blood alcohol concentration of $0.08 \mathrm{wt} / \mathrm{vol}$. Blood alcohol concentrations were verified using infrared spectrometry breath analysis. Participants then drove in the car-following scenario while legally intoxicated.

In the cell-phone session, three counterbalanced conditions were included: single-task baseline driving, driving while conversing on a hand-held cell phone, and driving while conversing on a hands-free cell phone. In both cell-phone conditions, the participant and a research assistant engaged in naturalistic conversations on topics that were identified on the first day as being of interest to the participant. To minimize interference from manual components of cell phone use, the call was initiated before participants began driving. 


\section{RESULTS AND DISCUSSION}

In order to better understand the differences between conditions, driving profiles were created by extracting 10 second epochs of driving performance that were time-locked to the onset of the pace car's brake lights. Each time that the pace car's brake lights were illuminated, the data for the ensuing 10 seconds were extracted and entered into a 32 X 300 data matrix (i.e., on the $\mathrm{j}^{\text {th }}$ occasion that the pace car brake lights were illuminated, data from the $1^{\text {st }} 2^{\text {nd }}, 3^{\text {rd }}, \ldots$, and $300^{\text {th }}$ observations following the onset of the pace car's brake lights were entered into the matrix $\mathrm{X}_{[\mathrm{j}, 1]}, \mathrm{X}_{[\mathrm{j}, 2]}, \mathrm{X}_{[\mathrm{j}, 3]} \ldots \mathrm{X}_{[\mathrm{j}, 300]}$; where $\mathrm{j}$ ranges from 1 to 32 reflecting the 32 occasions in which the participant reacted to the braking pace car). Each driving profile was created by averaging across $\mathrm{j}$ for each of the time points. We created profiles of the participant's braking response, driving speed, and following distance.

Figure 1 presents the braking profiles. In the baseline condition, participants began braking within 1 second of pace car deceleration. Similar braking profiles were obtained for both the cell phone and alcohol conditions. However, compared to baseline, when participants were legally intoxicated they tended to brake with greater force, whereas participant's reactions were slower when they were conversing on a cell phone. ${ }^{1}$

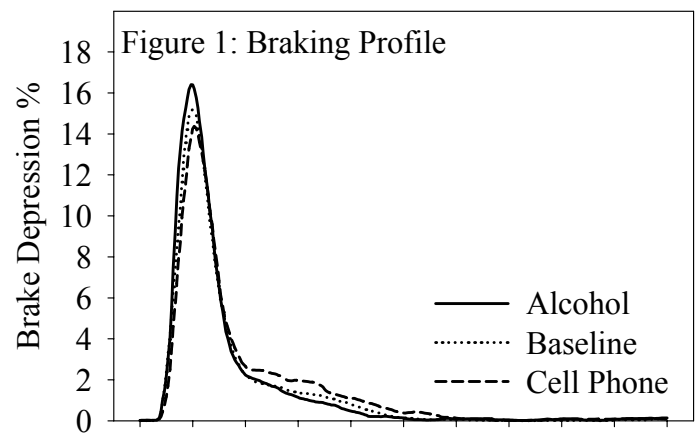

Figure 2 presents the driving speed profiles. In the baseline condition, participants began decelerating within 1 second of the onset of the pace car's brake lights; reaching minimum speed 2 seconds after the pace car began to decelerate, whereupon participants began a gradual return to pre-braking driving speed. When participants were legally intoxicated, they drove slower, but the shape of the speed profile did not differ from baseline. By

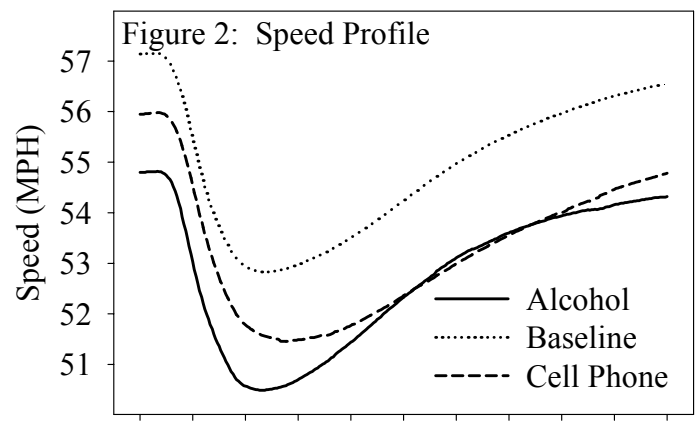
contrast, when participants were conversing on a cell phone it took them longer to recover their speed following braking.

Figure 3 presents the following distance profiles. In the baseline condition, participants followed approximately 28.5 meters behind the pace car and as the pace car decelerated, the following

\footnotetext{
${ }^{1}$ The data from hand-held and hands-free cell phone conditions were combined because preliminary analyses revealed no significant differences between these two modes of cellular communication (see below for details).
} 
distance decreased, reaching nadir approximately 2 seconds after the onset of the pace car's brake lights. When participants were legally intoxicated, they followed closer to the pace car, whereas participants increased their following distance when they were conversing on a cell phone.

Table 1 presents the six performance variables that were measured to determine how participants reacted to the vehicle braking in front of them. Brake-onset time is the time interval between the

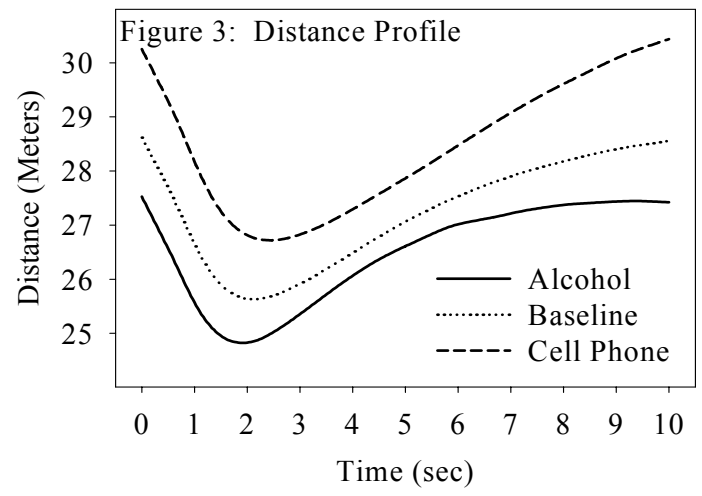
onset of the pace car's brake lights and the onset of the participant's braking response (expressed in milliseconds). Braking force is the maximum force that the participant applied to the brake pedal in response to the braking pace car (expressed as a percentage of maximum). Speed is the average driving speed of the participant's vehicle (expressed in miles per hour). Following distance is the distance between the pace car and the participant's car (expressed in meters). Half-recovery time is the time for participants to recover $50 \%$ of the speed that was lost during braking (expressed in seconds). Also shown in the table are the total number of collisions in each phase of the study. We used a Multivariate Analysis of Variance (MANOVA) followed by planned contrasts to provide an overall assessment of driver performance in each of the experimental conditions.

Table 1. Means and standard errors (in parentheses) for the Alcohol, Baseline, and CellPhone conditions.

\begin{tabular}{|c|c|c|c|}
\hline & Alcohol & Baseline & Cell Phone \\
\hline Total Accidents & \multirow{6}{*}{$\begin{array}{rr}0 & \\
888 & (51) \\
69.6 & (3.6) \\
52.8 & (.08) \\
26.5 & (1.7) \\
5.4 & (0.3)\end{array}$} & 0 & 3 \\
\hline Brake Onset Time (msec) & & $(58)$ & 1022 \\
\hline Braking Force ( $\%$ of maximum) & & $56.4 \quad(2.5)$ & 55.2 \\
\hline Speed (MPH) & & $(.08)$ & 53.2 \\
\hline Following Distance (meters) & & $(1.3)$ & 28.5 \\
\hline Recovery Time (sec) & & $(0.3)$ & $(0.4)$ \\
\hline
\end{tabular}

We performed an initial comparison of driving while using a hand-held versus hands-free cell phone. Both hand-held and hands-free cell phone conversations impaired driving. However, there were no significant differences in the impairments caused by these two modes of cellular communication $(\mathrm{F}(5,36)=1.33, \mathrm{p}>.27)$. Therefore, we collapsed across the hand-held and handsfree conditions for all subsequent analyses reported in this article. The observed similarity between hand-held and hands-free cell phone conversations is consistent with earlier work (Strayer \& Johnston, 2001; Strayer, Drews, \& Johnston, 2003) and suggests that the impairments to driving are mediated by a withdrawal of attention from the processing of information in the driving environment necessary for safe operation of a motor vehicle.

MANOVAs indicated that both cell-phone and alcohol conditions differed significantly from baseline $(\mathrm{F}(5,36)=3.44, \mathrm{p}<.01$ and $\mathrm{F}(5,36)=3.90, \mathrm{p}<.01$, respectively $)$. When drivers were conversing on a cell phone, they were involved in more rear-end collisions and their initial 
reaction to vehicles braking in front of them was slowed by $8.4 \%$, relative to baseline. In addition, compared to baseline, it took participants who were talking on the cell phone $14.8 \%$ longer to recover the speed that was lost during braking. Drivers using a cell phone attempted to compensate for their increased reaction time by driving $3.1 \%$ slower than baseline and increasing their following distance by $4.4 \%$.

By contrast, when participants were legally intoxicated, neither accident rates, nor reaction time to vehicles braking in front of the participant, nor recovery of lost speed following braking differed significantly from baseline. Overall, drivers in the alcohol condition exhibited a more aggressive driving style. They followed 3.0\% closer to the pace vehicle and braked with $23.4 \%$ more force than in baseline conditions. Most importantly, our study found that accident rates in the alcohol condition did not differ from baseline; however, the increase in hard braking that we observed is likely to be predictive of increased accident rates in the long run(e.g., Lee et al., 2002).

The MANOVA also indicated that the cell phone and alcohol conditions differed significantly from each other, $\mathrm{F}(5,36)=4.66, \mathrm{p}<.01$. When drivers were conversing on a cell phone, they were involved in more rear-end collisions, had a $7.5 \%$ greater following distance, and took $14.8 \%$ longer to recover the speed that they had lost during braking than when they were legally intoxicated. Drivers in the alcohol condition also applied 26.1\% greater braking pressure than drivers in the cell phone condition.

Taken together, we found that both intoxicated drivers and cell phone drivers performed differently from baseline, and that the driving profiles of these two conditions differed. Drivers in the cell phone condition exhibited a sluggish behavior (i.e., slower reactions), which they attempted to compensate for by increasing their following distance. Drivers in the alcohol condition exhibited a more aggressive driving style, in which they followed closer, necessitating braking with greater force. With respect to traffic safety, our data are consistent with Redelmeier and Tibshirani's (1997) earlier estimates. In fact, when controlling for driving difficulty and time on task, cell phone drivers may actually exhibit greater impairments (i.e., more accidents and less responsive driving behavior) than legally intoxicated drivers. These data also call into question driving regulations that prohibit hand-held cell phones and permit hands-free cell phones, because no significant differences were found in the impairments to driving caused by these two modes of cellular communication.

\section{ACKNOWLEDGMENTS}

Support for this study was provided through a grant from the Federal Aviation Administration (\# DTFA0202P09602). We wish to thank the Utah Highway Patrol for providing the breath analyzer and GE I-SIM for providing access to the driving simulator. Danica Nelson, Amy Alleman, and Joel Cooper assisted in the data collection. 


\section{REFERENCES}

Alm, H., \& Nilsson, L. (1995). The effects of a mobile telephone task on driver behaviour in a car following situation. Accident Analysis \& Prevention, 27(5), 707-715.

Briem, V., \& Hedman, L. R. (1995). Behavioural effects of mobile telephone use during simulated driving. Ergonomics, 38(12), 2536-2562.

Brookhuis, K. A., De Vries, G., \& De Waard, D. (1991). The effects of mobile telephoning on driving performance. Accident Analysis \& Prevention, 23, 309-316.

Cellular Telecommunications Industry Association,1250 Connecticut Avenue, NW Suite 800, Washington, DC 20036. Available at http://www.wow-com.com.

Goodman, M. F., Bents, F. D., Tijerina, L., Wierwille, W., Lerner, N., \& Benel, D. (1999). An Investigation of the Safety Implications of Wireless Communication in Vehicles. Report Summary. Department of Transportation electronic publication. Report summary available at http://www.nhtsa.dot.gov/people/injury/research/wireless/\#rep

Hahn, R. W., Tetlock, P. C., \& Burnett, J. K. (2000). Should you be allowed to use your cellular phone while driving? Regulation, 23, 46-55.

Hahn, R. W., \& Dudley, P. M. (In press). Cell phones and driving: The disconnect between law and policy analysis. Administrative Law Review.

Lee, J. D., McGehee, D. V., Brown, T. L., \& Reyes, M. L. (2002) Collision warning timing, driver distraction, and driver response to imminent rear-end collisions in a high-fidelity driving simulator. Human Factors, 44, 314-334.

McKnight, A. J. \& McKnight, A. S. (1993). The effect of cellular phone use upon driver attention. Accident Analysis \& Prevention, 25(3), 259-265.

Redelmeier, D. A., \& Tibshirani, R. J. (1997) Association between cellular-telephone calls and motor vehicle collisions. The New England Journal of Medicine, 336, 453-458.

Strayer, D. L., \& Johnston, W. A. (2001). Driven to distraction: Dual-task studies of simulated driving and conversing on a cellular phone. Psychological Science, 12, 462-466.

Strayer, D. L., Drews, F. A., \& Johnston, W. A. (2003). Cell phone induced failures of visual attention during simulated driving. Journal of Experimental Psychology: Applied, 9, 23-32. 